DOI 10.31489/2021No2/76-80

UDC 678.072:536.468

\title{
COMPARATIVE STUDY OF THE EFFECT OF FLAME RETARDANTS ON THE IGNITION TEMPERATURE OF EPOXY COMPOSITES
}

\author{
Amelkovich Yu.A., Nazarenko O.B., Smirnova I.N., Zadorozhnaya T.A. \\ National Research Tomsk Polytechnic University, Tomsk, Russia, olganaz@tpu.ru
}

\begin{abstract}
The disadvantage of polymeric materials, including epoxy resins, is their increased fire hazard. Reducing the flammability of polymeric materials is a serious problem that needs to be addressed. One of the ways to reduce the flammability of polymers is the introduction of special additives into the polymer matrix with flame retarding properties, which leads to a change in the nature of the processes occurring during the combustion of the polymer, or to blocking the combustion process with non-combustible or inhibiting substances. In this work, aluminum trihydroxide, melamine polyphosphate, and melamine poly(magnesium phosphate) were used as flame retardants to enhance the flame-resistant properties of epoxy resin. The filler loading in the epoxy composites was $10 \mathrm{wt} . \%$. The experimental studies have been carried out to determine the ignition temperature of the produced epoxy composites. The data obtained were compared with the ignition temperature of a control sample of epoxy resin without filler. The results indicated that the incorporation of all the flame retardants studied resulted in an increase in the ignition temperature. The ignition temperature of the samples filled with melamine polyphosphate and melamine poly(magnesium phosphate) increased by 28 and $11{ }^{\circ} \mathrm{C}$, respectively. However, the best result was obtained for a sample filled with aluminum trihydroxide: the ignition temperature of this sample was $40{ }^{\circ} \mathrm{C}$ higher than that of the unfilled epoxy resin.
\end{abstract}

Keywords: epoxy resin, composite, flame retardant, ignition temperature

\section{Introduction}

Epoxy resins are multipurpose oligomeric materials used for the production of compounds, composites, as well as for pouring various surfaces and making glue and sealant. Due to the unique combination of useful properties, epoxy resins are widely used in various areas of the national economy. From the whole variety of epoxy resins, an epoxy resin of ED-20 type stands out as an inexpensive, high-quality product. Epoxy resin ED-20 possesses such properties as high density, excellent hardness, good resistance to mechanical damage and moisture, heat resistance, dielectric and anti-corrosion ability, good adhesion to plastic, metal, glass, ceramics, wood, and many other materials, ease of use, low shrinkage. However, the flammability of epoxy resin, as well as most polymeric materials, is a disadvantage that limits the widespread use of polymeric materials in various industries and in everyday life [1]. The increase in the number of fires and material damage can be correlated with the increase in the consumption of polymer materials. Reducing the flammability and fire hazard of polymeric materials is one of the most important tasks, on the solution of which the further development of many sectors of the national economy depends. This task can be facilitated by the introduction of additives with flame retardant properties [2-5]. Such fillers can lead to a change in the nature of the polymer degradation process when heating or blocking the combustion process with non-combustible or inhibiting substances. Besides, the fillers also improve the physical, mechanical, and other functional properties of polymeric materials; their use contributes to reduce the consumption of valuable and often scarce raw materials. Therefore, this direction seems to be attractive from the point of view of the economics of the production of polymer material.

A large group of substances used as flame retardants is substances that upon heating endothermically decompose to form non-flammable products. One of such substances having flame retardant properties is boric acid. At the heating, boric acid releases water in the endothermic process that reduces polymer temperature and degradation. Also, nonflammable boron oxide forms on the polymer surface, which has a barrier effect and protects the polymer from flame action [6,7]. Aluminum trihydroxide (ATH) also belongs to the group of substances that have flame retardant properties due to endothermic decomposition upon heating [8-10]. It is known that the use of ATH is effective for reducing the flammability of the polymers, as a rule, when introduced in high concentrations of $\sim 50 \mathrm{wt} . \%$ and more, which contributes to the deterioration of physical, 
mechanical, technological, and operational properties, as well as to an increase in the cost of the material [11]. The new generation of flame retardants with excellent flame retardant properties includes melamine polyphosphate (MPP) and melamine poly(magnesium phosphate) (MPMgP) [12-16]. MPP combines the advantages of phosphorus and melamine based flame retardants and is widely used in various polymers to stimulate char formation. An important advantage of MPP is that it is environmentally friendly. It does not contain halogens, which are harmful to the environment.

The aim of this work was a comparative study of the effect of aluminum trihydroxide, melamine polyphosphate, and melamine polyphosphate magnesium on the ignition temperature of the epoxy composites based on epoxy resin ED-20.

\section{Experimental part}

\subsection{Sample preparation}

To obtain epoxy composites, we used epoxy resin of grade ED-20 and polyethylene polyamine (PEPA) as a hardener. The concentration of PEPA in the samples was 12 wt. \%. Aluminum trihydroxide (ATH), melamine polyphosphate (MPP), and melamine poly(magnesium phosphate) (MPMgP) were used as fillers. The concentration of the fillers in the compositions was $10 \mathrm{wt} \%$. The resulting mixtures were poured into silicone molds and cured at room temperature for $24 \mathrm{~h}$. For the experiment, five samples having a mass of $3 \mathrm{~g}$ of unfilled cured epoxy resin (E0) were prepared, as well as five samples for each type of filler. The samples had a cylindrical shape with the following dimensions: diameter $45 \mathrm{~mm}$, height $2 \mathrm{~mm}$. The images of the filled epoxy composites are shown in Fig. 1.

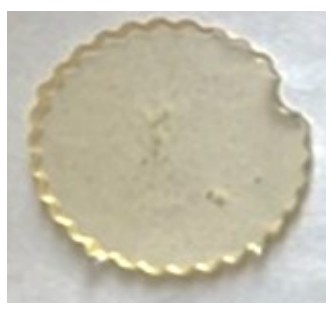

a)

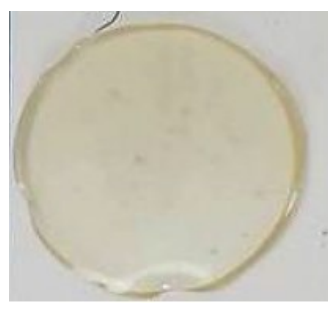

b)

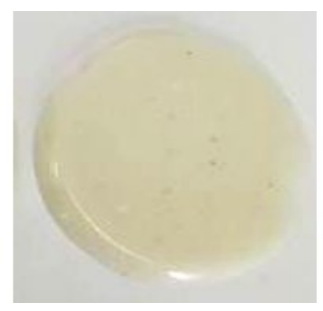

c)

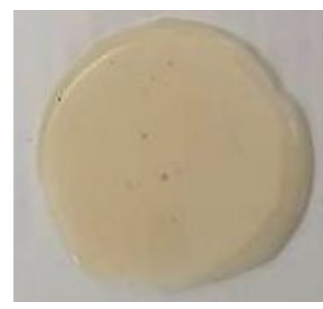

d)

Fig.1. Samples of epoxy composites: a) E0, b) E/ATH, c) E/MPP, d) E/MPP-Mg

\subsection{Characterization}

The thermogravimetric analysis (TGA) of the unfilled epoxy polymer was made using STA 449C Jupiter thermal analyzer (Netzsch). TGA curves were measured from $25{ }^{\circ} \mathrm{C}$ to $900{ }^{\circ} \mathrm{C}$ at a rate of heating $10{ }^{\circ} \mathrm{C} / \mathrm{min}$ under air atmosphere. Test method for determining ignition temperature of the epoxy composites was carried out according to the Russian regulatory document GOST 12.1.044-2018 "Occupational safety standards system. Fire and explosion hazard of substances and materials. Nomenclature of indices and methods of their determination". The experimental method for determining the ignition temperature consists in heating the substance, at which the evolved gases are ignited, after which the presence of ignition is recorded at a set temperature. The tests were carried out on an installation for determining the ignition temperature and autoignition temperature of solids and materials at a constant temperature of the reaction furnace (Fig. 2).

The principle of operation of the installation is based on setting a constant temperature regime in a reaction furnace $\left(400{ }^{\circ} \mathrm{C}\right)$ and exposure to a burner flame. After introducing the test samples into the reaction furnace, the temperature indicators were monitored. To calculate the ignition temperature of the investigated substance, the arithmetic mean of two temperatures differing by no more than $10^{\circ} \mathrm{C}$ was taken.

\section{Results and discussion}

The results of thermal analysis obtained for the unfilled epoxy sample E0 are shown in Fig. 3. Thermooxidative degradation of the epoxy resin was studied using the thermogravimetric method (TG), differential thermogravimetry (DTG), and differential scanning calorimetry (DSC). The initial temperature of degradation of the sample E0 at which the mass loss is $5 \%$ was found to be $266{ }^{\circ} \mathrm{C}$. Thermo-oxidative degradation of the epoxy polymer occurs in three stages. 


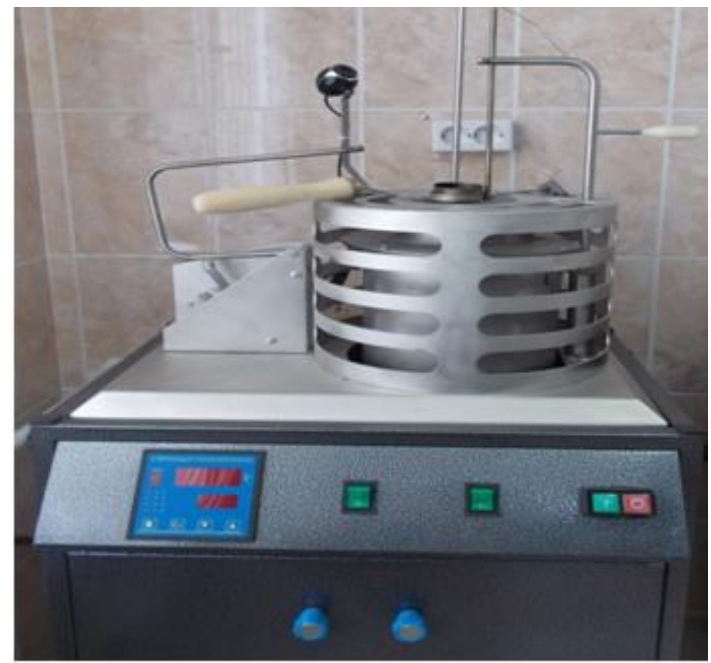

Fig.2. Installation for determining the ignition temperature

Three exothermic peaks on the DSC curve are caused by the following processes: homolytic scission of chemical bonds, the depolymerization of polymeric chains followed by a primary carbonaceous char formation, and the oxidation of formed carbonaceous char $[17,18]$. The values of the maximum temperature at the first, second, and third peaks for the sample E0 were 285,428 , and $522{ }^{\circ} \mathrm{C}$, respectively. The thermo-oxidative degradation of the unfilled epoxy polymer was finished at $\sim 600^{\circ} \mathrm{C}$.

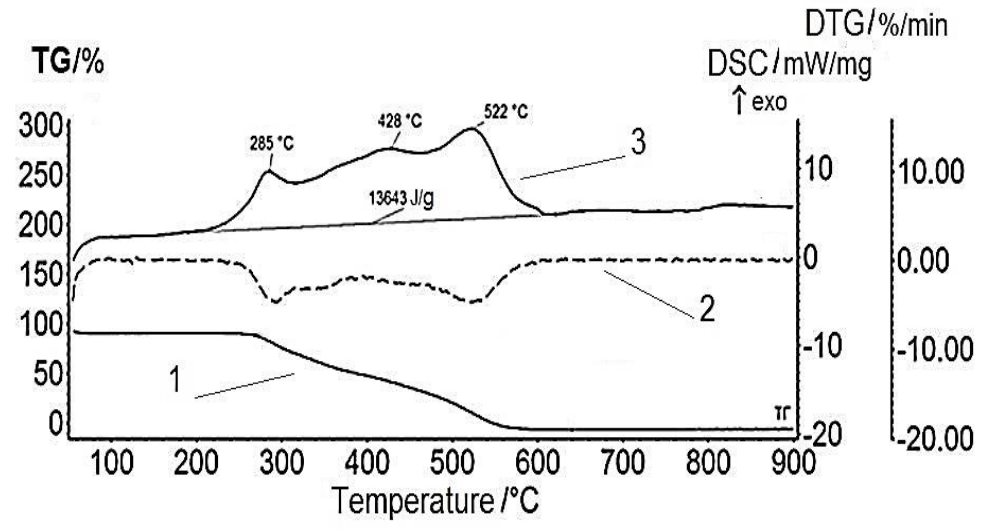

Fig.3. TG (1), DTG (2) and DSC (3) curves of the unfilled epoxy polymer

One of the characteristics of the flammability of materials is ignition temperature. Ignition temperature means the lowest temperature of a substance at which, under the conditions of special tests, a substance emits flammable vapors and gases at such a rate that, when exposed to an ignition source, ignition is observed. The value of the ignition temperature of the test sample must be known to develop measures to ensure fire safety, as well as to determine the degree of flammability of substances. The results of the testing for the ignition temperature of epoxy composites are presented in Table 1. Fig. 4 shows the remains of the materials obtained during testing.

According to the results obtained, the ignition temperature of the control sample E0 was $307{ }^{\circ} \mathrm{C}$. The maximum ignition was obtained for the sample E/ATH and it was $40^{\circ} \mathrm{C}$ higher than that of the control sample E0. When heated, ATH decomposes in the endothermic reaction with the release of water and the formation of non-combustible aluminum oxide [8-10]:

$$
2 \mathrm{Al}(\mathrm{OH})_{3} \rightarrow \mathrm{Al}_{2} \mathrm{O}_{3}+3 \mathrm{H}_{2} \mathrm{O}, \Delta \mathrm{H}=298 \mathrm{~kJ} / \mathrm{mol} \text {. }
$$

Thus, the introduction of ATH into the polymer promotes heat removal and dilution of the formed combustible gases during heating and combustion of the polymer. Additionally, the layer of aluminum oxide on the polymer surface provides a physical barrier and prevents the polymer from the action of the flame. The ignition temperature for the samples E/MPP and E/MPMgP was higher by $28^{\circ} \mathrm{C}$ and $11{ }^{\circ} \mathrm{C}$, correspondingly, 
in comparison with that of the sample E0. The residue after the test was the largest for the samples E/ATH and E/MPP. The sample E/MPMgP burned out almost completely.

Table 1. Ignition temperature of epoxy composites.

\begin{tabular}{cc}
\hline Sample & $T_{i g}{ }^{\circ} \mathrm{C}$ \\
\hline E0 & 307 \\
E/ATH & 347 \\
E/MPP & 335 \\
E/MPP-Mg & 318 \\
\hline
\end{tabular}

MPP decomposes endothermically above $350{ }^{\circ} \mathrm{C}$, acting as a heat sink and cooling the combustion zone of the polymer. The released phosphoric acid additionally reacts with the polymer to form carbonaceous char, preventing oxidation of the combustible polymer surface $[12,13]$. At the same time, the formation of nitrogen during the decomposition of melamine intensifies the formation of a char layer for additional protection of the polymer.

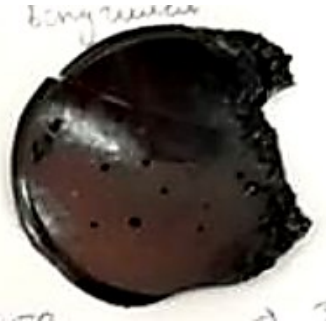

a)

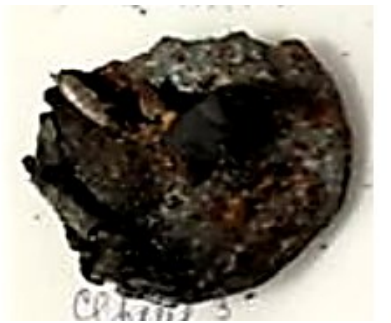

b)

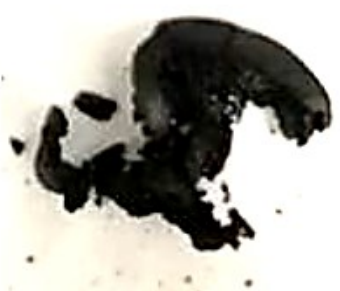

c)

Fig.4. Samples of epoxy composites after testing for ignition temperature:

a) E/ATH, b) E/MPP, c) E/MPP-Mg

The results obtained can be explained by the thermal stability of the unfilled epoxy polymer and used in this study flame retardants. It is known that at the heating ATH begins to decompose at the temperature $190{ }^{\circ} \mathrm{C}$ with maximum release of water at $350{ }^{\circ} \mathrm{C}$ [10], while according to the results of thermal analysis, the initial temperature of degradation of the unfilled epoxy polymer is $266^{\circ} \mathrm{C}$. When the epoxy polymer filled with ATH is heated, ATH decomposes endothermically in aluminum oxide and water, absorbing heat. Additionally, the water formed in this process dilutes the concentration of other gaseous decomposition products and lowers the flame temperature. Upon further heating, solid residues are formed, creating a barrier against oxygen and heat. The MPP starts to degrade at $350{ }^{\circ} \mathrm{C}$, the temperature of $5 \mathrm{wt} . \%$ mass loss for MPP is $383{ }^{\circ} \mathrm{C}$ and for MPMgP is $368{ }^{\circ} \mathrm{C}[13,14]$. When the epoxy polymer is heated to such values of temperature, the epoxy polymer loses 52 and $49 \%$ by weight, respectively. The contribution of the flame retardants MPP and MPMgP to the flame suppression process begins at a later stage in comparison with the epoxy polymer filled with ATH.

The obtained results can be compared with the result for determining the ignition temperature of epoxy composites filled with boric acid (10 wt. \%) and the composition of boric acid (10 wt. \%) and iron nanopowder (5 wt. \%) [19]. The ignition temperature was found to be increased to $317^{\circ} \mathrm{C}$ for the sample filled with boric acid and $322{ }^{\circ} \mathrm{C}$ for the sample filled with boric acid in combination with iron nanopowder.

It should be noted that these conclusions relate to the epoxy resin of the ED-20 type investigated in this work. Thus, among the studied flame retardants, the use of ATH leads to the greatest increase in the ignition temperature and can be recommended for the development of polymer composite materials based on the epoxy resin ED-20.

\section{Conclusions}

In this work, the epoxy composites were prepared by incorporation of three kinds of flame retardants in the epoxy matrix: aluminum trihydroxide, melamine polyphosphate, and melamine poly(magnesium phosphate). The concentration of each flame retardant in the epoxy resin was $10 \mathrm{wt}$ \%. The test for determining the ignition temperature of the epoxy composites and unfilled epoxy resin was carried out 
according to Russian regulatory document GOST 12.1.044-2018. Among the studied flame retardants, when they were introduced into the epoxy resin to reduce flammability, aluminum trihydroxide showed the best results: the ignition temperature was $40{ }^{\circ} \mathrm{C}$ higher than that of the unfilled epoxy resin ED-20. The use of melamine polyphosphate and melamine poly(magnesium phosphate) as a flame retardant for other types of epoxy resins requires clarification and more detailed studies, in particular, using thermal analysis. In our future work, we will study the effect of aluminum trihydroxide on the characteristics of the flammability of epoxy polymers in combination with nanodispersed fillers - metal nanoparticles. The results of this study can be applied to study and develop polymer materials with reduced flammability.

\section{Acknowledgments}

This research was supported by Tomsk Polytechnic University development program.

\section{REFERENCES}

1 Jin F.-L., Li X., Park S.-J. Synthesis and application of epoxy resins: A review. J. Ind. Eng. Chem., 2015, Vol. 29, pp. $1-11$

2 Laoutid F., Bonnaud L., Alexandre M., Lopez-Cuesta J.M., Dubois P. New prospects in flame retardant polymer materials: from fundamentals to nanocomposites. Mater. Sci. Eng. R, 2009, Vol. 63, p. 100-125

3 Camino G., Costa L. Performance and mechanisms of fire retardants in polymers - a review. Polym. Degradat. Stabil., 1988. Vol. 20, p. 271-294

4 Morgan A.B., Gilman J.W. An overview of flame retardancy of polymeric materials: Application, technology, and future directions. Fire Mater., 2013, Vol. 37, p. 259-279

5 He W., Song P., Yu B., Fang Z., Wang H. Flame retardant polymeric nanocomposites through the combination of nanomaterials and conventional flame retardants. Prog. Mater. Sci., 2020, Vol. 114, pp.100687

6 Visakh P.M., Nazarenko O.B., Amelkovich Y.A., Melnikova T.V. Effect of zeolite and boric acid on epoxy-based composites.Polym. Adv. Technol. 2016, Vol. 27, pp. $1098-1101$.

7 Balci S., Sezgi N.A., Eren E. Boron oxide production kinetics using boric acid as raw material. Ind. Eng. Chem. Res. 2012, Vol. 51, Iss. 34, pp. 11091-11096.

8 Witkowski A., Stec A.A., Hull T.R. The influence of metal hydroxide fire retardants and nanoclay on the thermal decomposition of EVA. Polym. Degrad. Stab., 2012, Vol. 97, pp. $2231-2240$.

9 Unlu S.M., Dogan S.D., Dogan M. Comparative study of boron compounds and aluminium trihydroxide as flame retardant additives in epoxy resin. Polym.Advan. Technol., 2014, Vol. 25, pp. 769-76.

10 Frańczak A., Oleksy M., Oliwa R., Budzik G. Polyethylene composites flame retarded with aluminum hydroxide as coatings for electrical cables. Polymery, 2018, Vol. 63(6), p. 458-461.

11 Wypych G. Fillers - Origin, chemical composition, properties, and morphology. In: Handbook of Fillers. Ed.: G. Wypych. Toronto: ChemTec Publishing. 2016, pp. $13-266$.

12 Chen W.Y., Wang Y.Z., Chang F.C. Thermal and flame retardation properties of melamine phosphate-modified epoxy resins. J Polym Res., 2004, Vol. 11, pp. $109-117$.

13 Müller P., Schartel B. Melamine poly(metal phosphates) as flame retardant in epoxy resin: Performance, modes of action, and synergy. J. Appl. Polym. Sci., 2016, pp. 43549.

14 Lubczak J.M., Lubczak R. Melamine polyphosphate - the reactive and additive flame retardant for polyurethane foams. Acta Chim Slov., 2016, Vol. 63, pp. $77-87$.

15 Liu S.-H., Kuan C.-F., Kuan H.-C., Shen M.-Y., Yang J.-M., Chiang C.-L. Preparation and flame retardance of polyurethane composites containing microencapsulated melamine polyphosphate. Polymers, 2017, Vol. 9, pp. 407.

16 Ma X., Meng X., Li Z., Xiao Q., Wang Z., Yan K. Study of the influence of melamine polyphosphate and aluminum hydroxide on the flame propagation and explosion overpressure of aluminum magnesium alloy dust. J. Loss Prev. Process Ind., 2020, Vol. 68, pp.104291

17 Bellenger V., FontainemE., FleishmannA., SaporitoJ., Verdu J. Thermogravimetric study of amine cross-linked epoxies. Polym. Degrad. Stab. 1984, Vol. 9, pp. $195-208$.

18 Kandola B.K., Biswas B., Price D., Horrocks A.R. Studies on the effect of different levels of toughener and flame retardants on thermal stability of epoxy resin. Polym. Degrad. Stab., 2010, Vol. 95, pp. 144-152

19 Nazarenko O., Lipchansky D., Smirnova I. Effect of iron nanopowder on flammability of epoxy composites. IOP Conf. Ser.: Mater. Sci. Eng., 2020, Vol. 1019, pp. 012001. 